\title{
Viabilidade celular de condrócitos expostos à bupivacaína, mepivacaína e ropivacaína
}

Gabriele Biavaschi Silva ${ }^{[a]}$,Stefano Leite Dau ${ }^{[a]}$, Flávio De La Côrte ${ }^{[a]}$, Karin Érica Brass ${ }^{[a]}$, Heloisa Einloft Palma ${ }^{[b]}$, Miguel Gallio[a], Alexandre Krause ${ }^{[a]}$, Luciana Fontanari Krause ${ }^{[c]}$, Kalyne Bertolin ${ }^{[a]}$, Julien Wergutz ${ }^{[c]}$

\footnotetext{
[a] Universidade Federal de Santa Maria (UFSM), Santa Maria, RS, Brasil

[b] Universidade de Cruz Alta (UNICRUZ), Cruz Alta, RS, Brasil

${ }^{[c]}$ Centro Universitário Franciscano (UNIFRA), Santa Maria, RS, Brasil
}

*Autor correspondente

e-mail: gabibiavaschi@hotmail.com

\section{Resumo}

A mepivacaína é o anestésico local mais utilizado nos bloqueios anestésicos intra-articulares (IA) durante os exames de claudicação nos Estados Unidos e na Europa por apresentarem menor efeito condrotóxico, contudo o seu uso na rotina clínica no Brasil é limitado devido ao difícil acesso e custo desta droga. A ropivacaína é um anestésico local de longa duração, semelhante à bupivacaína, disponível no Brasil, porém sem relatos de seu efeito sobre condrócitos equinos. Por este motivo, o presente estudo avaliou, através de cultivos de condrócitos em monocamada, os possíveis efeitos tóxicos da ropivacaína 0,75\%, mepivacaína 2\% e bupivacaína 0,5\%. Fragmentos de cartilagem foram obtidos de forma asséptica por meio de artrotomia de articulações metacarpofalangeanas provenientes de peças de frigorífico. Estas articulações não apresentavam alterações características de doença articular ao exame radiológico e ao exame macroscópico no momento da coleta de cartilagem. Os condrócitos foram obtidos após a digestão enzimática dos fragmentos de cartilagem com pronase $1 \%$ por 30 minutos (') e posteriormente com colagenase $0,4 \%$ por 180'. As células foram ressuspendidas e cultivadas em meio DMEM suplementado com penicilina (60 U/ $\mathrm{mL})$, estreptomicina ( $60 \mu \mathrm{g} / \mathrm{mL})$ e glutamina $(2 \mathrm{mmol} / \mathrm{L})$ em garrafas de cultivo celular incubadas a $37^{\circ} \mathrm{C}$, em estufa umidificada com $5 \%$ de $\mathrm{CO}_{2}$. A viabilidade celular foi mensurada por meio de citometria de fluxo (\%) e pelo método colorimétrico MTT (\%). Para o primeiro teste, os condrócitos foram semeados em placas celulares de seis poços e quando atingiram confluência média de 80\% foram expostos a 30' dos seguintes tratamentos: ropivacaína 0,75\% (G1), solução fisiológica 0,9\% (G2), mepivacaína 2\% (G3) e bupivacaína 0,5\% (G4). Posteriomente, o sobrenadante foi removido e as células foram tripsinizadas e suspensas em meio de cultivo para avaliação por citometria de fluxo. Para a avaliação pelo método colorimétrico de MTT, 
os tratamentos foram removidos após o período de 30', $100 \mu \mathrm{L}$ de DMEM e $10 \mu \mathrm{L}$ de solução de MTT foram adicionados, as células foram incubadas por 3 a 4 horas e, depois, as placas foram esvaziadas e $100 \mu \mathrm{L}$ de dimetil sulfóxido adicionado para dissolver os cristais de formazan que se formaram pela degradação do MTT. As amostras foram realizadas em duplicata biológica e os resultados de viabilidade foram expressos em porcentagens como média \pm desvio padrão. A citometria de fluxo revelou uma taxa de viabilidade celular de 96,72 $\pm 1,29 \%$ nas células tratadas com ropivacaína 7,5 mg/ml, 99,01 $\pm 0,11 \%$ nas tratadas com solução salina, $97,47 \pm 0,74 \%$ nas tratadas com mepivacaína $20 \mathrm{mg} / \mathrm{ml}$ e 90,81 $\pm 3,97 \%$ nos tratamentos com bupivacaína $5 \mathrm{mg} / \mathrm{ml}$. Na avaliação pelo método de MTT a viabilidade foi de $48,65 \pm 0,92 \%$ no G1, $54,15 \pm 3,04 \%$ no G2, 31,25 $\pm 1,48 \%$ no G3 e $20,45 \pm 3,04 \%$ no G4. Estes resultados refletem resultados parciais do experimento, com apenas duas repetições, o que não permitiu análise estatística. A menor viabilidade observada através do método de MTT pode estar associada à existência de dano mitocondrial nas células, apesar da membrana celular ainda estar íntegra, identificando fases mais iniciais da morte dos condrócitos. Através do método de MTT pode-se observar, assim como em condrócitos humanos, que as células tratadas com ropivacaína apresentaram viabilidade celular superior às células tratadas com mepivacaína e bupivacaína, sugerindo menor toxicidade da ropivacaína em relação aos outros anestésicos locais. A mensuração da taxa de viabilidade celular indica que a ropivacaína é um fármaco a ser considerado no uso IA, contudo, mais estudos devem ser conduzidos a fim de avaliar a segurança da droga.

Palavras-chave: Viabilidade de condrócitos. Toxicidade. Bupivacaína. 